\title{
QUEEN'S
QNEIVERSITY
BELFAST
}

\section{Removal of microcystins from a waste stabilisation lagoon: Evaluation of a packed-bed continuous flow TiO2 reactor}

Pestana, C. J., Hobson, P., Robertson, P. K. J., Lawton, L. A., \& Newcombe, G. (2020). Removal of microcystins from a waste stabilisation lagoon: Evaluation of a packed-bed continuous flow TiO2 reactor. Chemosphere, 245, [125575]. https://doi.org/10.1016/j.chemosphere.2019.125575

\section{Published in:}

Chemosphere

\section{Document Version:}

Peer reviewed version

Queen's University Belfast - Research Portal:

Link to publication record in Queen's University Belfast Research Portal

\section{Publisher rights}

Copyright 2019 Elsevier.

This manuscript is distributed under a Creative Commons Attribution-NonCommercial-NoDerivs License

(https://creativecommons.org/licenses/by-nc-nd/4.0/), which permits distribution and reproduction for non-commercial purposes, provided the author and source are cited.

\section{General rights}

Copyright for the publications made accessible via the Queen's University Belfast Research Portal is retained by the author(s) and / or other copyright owners and it is a condition of accessing these publications that users recognise and abide by the legal requirements associated with these rights.

Take down policy

The Research Portal is Queen's institutional repository that provides access to Queen's research output. Every effort has been made to ensure that content in the Research Portal does not infringe any person's rights, or applicable UK laws. If you discover content in the Research Portal that you believe breaches copyright or violates any law, please contact openaccess@qub.ac.uk. 
1 Removal of microcystins from a waste stabilisation lagoon: Evaluation of a

2 packed-bed continuous flow $\mathrm{TiO}_{2}$ reactor

3

4 Carlos J. Pestanaa,b*, Peter Hobsona , Peter K. J. Robertsonc, Linda A. Lawton ${ }^{\mathrm{b}}$,

5 Gayle Newcombe ${ }^{a}$

6

7 a Australian Water Quality Centre, South Australian Water Corporation, 250 Victoria

8 Square, Adelaide, SA 5000, Australia

9

b School of Pharmacy and Life Sciences, Robert Gordon University, Sir lan Wood Building, Garthdee Road, AB10 7GJ, Aberdeen, UK

12

c School of Chemistry and Chemical Engineering, Queen's University, David Keir

Building, 39 Stranmillis Road, BT9 5 AG, Belfast, UK

15

${ }^{*}$ Corresponding author:

17 Email: c.pestana@rgu.ac.uk

Tel: 00441224262847

Declaration of Interest: None.

Highlights:

- Removal of microcystins from waste stabilisation lagoon

- Continuous flow, packed bed $\mathrm{TiO}_{2}$ reactor design

- Significant removal of microcystins and improvement of water quality 
- Natural organic matter decreases but does not inhibit microcystin removal

- Viable treatment option if optimised for toxin and cell removal

Graphical abstract:

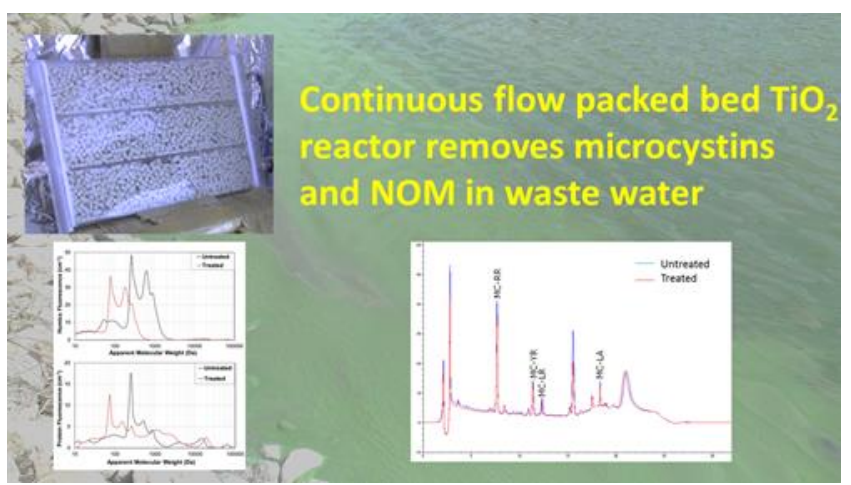

\section{Abstract}

Photocatalysis has been shown to successfully remove microcystins (MC) in laboratory experiments. Most research to date has been performed under ideal conditions in pure or ultrapure water. In this investigation the efficiency of photocatalysis using titanium dioxide was examined in a complex matrix (waste stabilisation lagoon water). A flow-through photocatalytic reactor was used to photocatalyse four commonly occurring microcystin analogues (MC-YR, MC-RR, MC-LR, and MC-LA). Up to $51 \%$ removal for single MC analogues in waste lagoon water was observed. Similar removal rates were observed when a mixture of all four $\mathrm{MC}$ analogues was treated. Although treatment of MC-containing cyanobacterial cells of Microcystis aeruginosa resulted in no decline in cell numbers or viability with the current reactor design and treatment regime, the photocatalytic treatment did improve the overall quality of waste lagoon water. This study demonstrates that 
despite the presence of natural organic matter the microcystins could be successfully degraded in a complex environmental matrix.

Keywords: waste water treatment; cyanobacteria; photocatalysis; titanium dioxide; microcystin

\section{Introduction}

Cyanobacteria commonly occur in waste stabilisation lagoons, usually applied to remove phosphates and nitrates, within waste water treatment plants (Barrington et al., 2013; Martins et al., 2011). Certain cyanobacterial strains are capable of producing toxic secondary metabolites; especially the microcystins (MC) are of rising worldwide concern and responsible for the intoxication of humans and animals (Ghadouani and Coggins, 2011; Paerl and Huisman, 2008). MC are hepatotoxic cyclic peptides with a wide variety of congeners (246 to date) (Spoof and Catherine, 2017); one of the most common and toxic congeners is MC-LR (LD50 in mice $50 \mu \mathrm{g} \mathrm{kg}^{-1}$ ) (Sivonen and Jones, 1999). The World Health Organisation has published a recommended maximum allowable level for MC-LR of $1 \mu \mathrm{g} \mathrm{L}^{-1}$ in drinking water (WHO, 2017). While the waste lagoon effluent is not destined for human consumption, it can be used for irrigation of crops and recreational areas or discharged into receiving water bodies (Barrington et al., 2013). While the health and safety risk is comparatively low when compared to drinking water MCs can nonetheless pose significant ecological issues. Additionally cyanobacteria and/or their secondary metabolites are known to hinder waste water treatment processes (Martins et al., 2011; Praptiwi et al., 2017). 
Chemical oxidation with hydroxyl radicals $(\mathrm{OH} \cdot)$ generated by UV titanium dioxide $\left(\mathrm{TiO}_{2}\right)$ photocatalysis has previously been shown to successfully remove MC-LR and other congeners (Lawton and Robertson, 1999; Liu et al., 2002; Pestana, 2012; Pestana et al., 2015). However, there remain barriers to the application of this technology: the form of the catalytic material and subsequent separation of the catalyst from water, as well as the development of a continuous flow reactor to allow incorporation of the process in-line with treatment processes. Nano-particulate $\mathrm{TiO}_{2}$ (e.g. Degussa P25) has a large reactive surface area (Lawton and Robertson, 1999; Robertson et al., 1997), however, separation from water is challenging and prevents ease of use. Pelletised $\mathrm{TiO}_{2}$ facilitates separation from the sample matrix, however, effectiveness is reduced compared to nano-particulate $\mathrm{TiO}_{2}$ (Liu et al., 2009). Coated surfaces have been demonstrated to be as effective as nano-particulates however, these require a specialised, energy demanding production process (Pelaez et al., 2010). Furthermore, previous studies (Lawton and Robertson, 1999; Liu et al., 2009, 2002; Pelaez et al., 2010; Robertson et al., 1997) evaluated removal of MC in pure water, whereas, in environmental applications other organic material would be present, competing with MC. Therefore, real-life applications will potentially experience decreasing effectiveness or alternatively requiring longer exposure times. Pestana et al. (2014) have recently successfully demonstrated the UV photocatalytic removal of the commonly problematic taste and odour compounds geosmin and 2methylisoborneol with a packed-bed, continuous flow reactor using pelletised $\mathrm{TiO}_{2}$ in water from a fish-farm raceway. This work demonstrated that a flow-through reactor design with pelletised $\mathrm{TiO}_{2}$ is capable of removing trace water contaminants from a complex matrix. 
In the present study, a bench scale packed-bed, continuous flow reactor was

designed and used to demonstrate the UV photocatalysis of four commonly occurring $\mathrm{MC}$ congeners in waste lagoon water using pelletised $\mathrm{TiO}_{2}$. Waste stabilisation lagoon water presents an extremely complex sample matrix with high dissolved organic material which present a challenge to the successful removal of toxic contaminants like MC, as natural organic matter (NOM) can exhibit radical scavenging properties and light attenuation. This represents an important step towards the implementation of the full-scale application of continuous-flow $\mathrm{TiO}_{2} / \mathrm{UV}$ in water treatment applications.

\section{Materials and methods}

\subsection{Chemicals}

Hombikat K01/C titanium dioxide pellets (Supporting Information, S1) were obtained from Sachtleben Chemie (Germany) and rinsed thoroughly with reverse osmosis water $(\mathrm{RO})$ before use for fines removal. Microcystin analogues were obtained from Enzo Life Science AG (Switzerland). All solvents were obtained from Merck (Germany) and were of analytical grade.

\subsection{Photocatalysis of toxins}

A packed-bed continuous flow reactor was constructed and connected to a $3 \mathrm{~L}$ reservoir. In brief, the reactor consisted of a three channel (connected in a serpentine fashion) sheet of polycarbonate with a guaranteed 95\% UV permeability (Evonik, Germany) that was packed with pelletised $\mathrm{TiO}_{2}$ (Sachtleben Chemie, Germany). Silicone tubing and a peristaltic pump recircled the test solution through the reactor (Supporting Information, S2). A test solution (autoclaved lagoon water or 
$118 \mathrm{RO}$ filtered water) with $30 \mu \mathrm{g} \mathrm{L}^{-1}$ of the relevant microcystin analogue was prepared.

119 In the case of the $\mathrm{MC}$ analogue mixture, $10 \mu \mathrm{g} \mathrm{L}^{-1}$ of each of the four analogues under investigation (MC-YR, -RR, -LR,-LA) were added. Initially, a T0 sample was taken, followed by the entire experimental volume of the reservoir passing through the reactor three times (contact time $1.9 \mathrm{~min}$; see $\mathrm{S} 2$ for calculation of contact time) without irradiation to determine the dark absorption, i.e. the amount the $\mathrm{MC}$ concentration decreases in the absence of UV which is attributed to adsorption onto the $\mathrm{TiO}_{2}$. The time was deemed sufficient based on the results of the controls that were performed in the dark and the absence of UV irradiation (Supporting Information, S3). Following this, the test solution was recycled through the illuminated reactor for a total illuminated contact time of 14.3 min with samples taken at known intervals.

\subsection{Photocatalysis of Microcystis aeruginosa}

A 17 day old culture of Microcystis aeruginosa 338 (Australian Water Quality Centre) was aseptically separated from growth medium by centrifugation (15 min, $1640 \times \mathrm{g}$ at room temperature). The cell pellets were re-suspended in waste lagoon water (100 $\mathrm{mL}$ ). A sample was taken, fixed with Lugol's solution, and cell enumeration was performed using a Sedgewick-Rafter cell and light microscopy (Nikon 50i, Japan). The culture was analysed by flow cytometry using fluorescein diacetate (FDA) and SYTOX Green dyes to measure cell viability and membrane integrity using previously published protocols (Hobson et al., 2012). A cell suspension was prepared $\left(3 \times 10^{5}\right.$ alive cells $\left.\mathrm{mL}^{-1}\right)$ in waste stabilisation lagoon water. The photocatalysis experiment was then performed as before (section 2.2) without the 
addition of MC. Controls were performed in the absence of UV irradiation and in the absence of catalyst.

\subsection{Analysis}

Samples for MC analysis were concentrated by solid phase extraction (SPE) through C18 cartridges (Waters, United Kingdom) as previously described (Nicholson et al., 1994). After SPE the eluted samples were reduced to dryness by centrifugal evaporation in a MiVac DuoConcentrator attached to a MiVac DuoPump (both GeneVac, United Kingdom) and re-suspended in 50\% aqueous methanol (1 mL), filtered $(0.22 \mu \mathrm{m})$, and analysed by HPLC. The samples from the photocatalysis of the MC-containing $M$. aeruginosa were filtered (GF/C; Whatman, UK) to separate cells from the water. The filter disks containing the cells were frozen $\left(-20^{\circ} \mathrm{C}\right)$ then extracted in $10 \mathrm{~mL}$ of $80 \%$ methanol for 60 min with occasional agitation (Lawton et al., 1994). The extract was reduced to dryness by centrifugal evaporation, resuspended in $50 \%$ methanol $(1 \mathrm{~mL})$, filtered $(0.22 \mu \mathrm{m})$, and analysed. The $\mathrm{MC}$ in the cell filtrate was concentrated as before by SPE to determine extra-cellular MC concentration.

All processed samples were analysed on an Agilent Technologies 1100 series high performance liquid chromatography (HPLC) system consisting of a quaternary pump (G1311A), degasser (G1379A), auto sampler (G1313A), column compartment (G1316A) and photodiode array detector (G1315B) using the previously published method of Ho et al. (2006). The extraction recoveries for the above method are stated as $>95 \%$ (Ho et al., 2006a). Samples of treated and untreated waste lagoon water, along with the light and dark controls, were analysed by high performance size exclusion chromatography (HPSEC) for analysis of the effect the UV/TiO 2 
treatment on the protein and humic portions of the NOM. For this, samples were analysed on a Waters Alliance 2690 separations module and 996 photodiode array detector (PDA) at $260 \mathrm{~nm}$ (Waters Corporation, USA) according to a method described in Fabris et al. (2008). A 0.1 M Phosphate buffer with $1.0 \mathrm{M} \mathrm{NaCl}$ was passed through a packed silica column (Shodex KW802.5; Showa Denko, Japan) at a flow rate of $1.0 \mathrm{~mL} \mathrm{~min}{ }^{-1}$. The effect of the treatments on water quality parameters was also monitored (Supporting Information S4).

\section{Results and Discussion}

\subsection{Evaluation of reactor performance}

Previously published studies of $\mathrm{UV} / \mathrm{TiO}_{2}$ removal have almost exclusively employed pure water, thus a comparison between the removal in pure water and waste lagoon water was performed. The matrices tested were RO water and waste lagoon water (see Supporting Information S4 for water quality parameters of untreated lagoon water). The removal of MC-LR dropped from $84 \%$ in RO water to $46 \%$ in waste lagoon water under the same experimental conditions (figure 1), with the most probable explanation being the presence of competing natural organic matter (NOM). Although another contributing factor could be the presence of inorganic ions that adhere to the $\mathrm{TiO}_{2}$ and inactivate binding places by blocking them for organic molecules (Umar and Aziz, 2013), indicated by a decrease in conductivity from 1173 to $976 \mu \mathrm{S} \mathrm{cm}{ }^{-1}$ (Supporting Information, S4). Furthermore, NOM can act as a scavenger of the surface-generated oxidising species (e.g. $\mathrm{OH}$ and superoxide radicals) produced by interaction of the catalyst and the UV irradiation in the aqueous matrix (Feitz et al., 1999). Pelaez et al. (2011) also found that NOM had an inhibitory effect on the photocatalysis of MC-LR when they investigated the 
201

photocatalytic breakdown of MC-LR both in the presence of naturally occurring humic and fulvic acids.

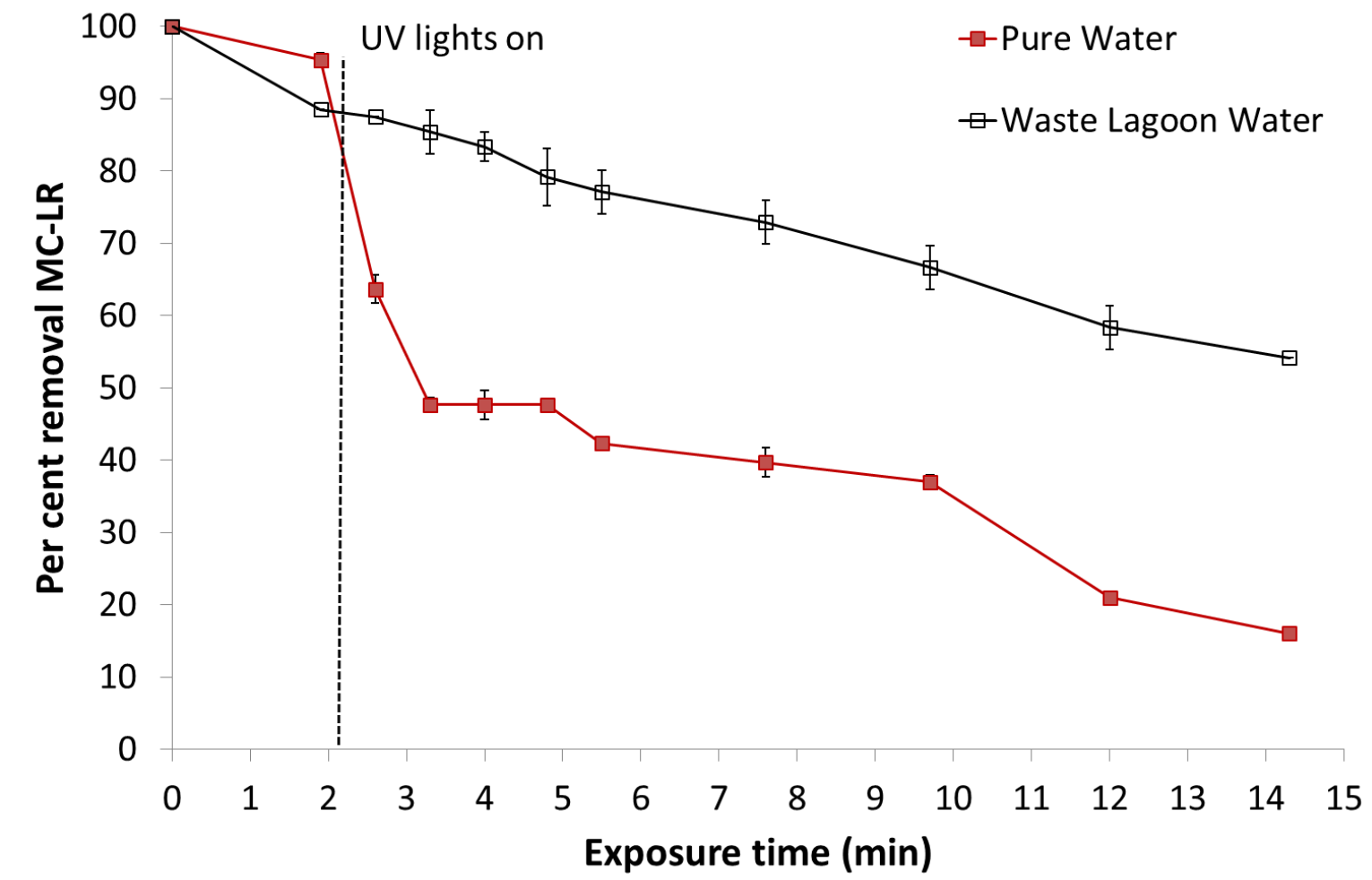

Figure 1: Removal of MC-LR (initial concentration $30 \mu \mathrm{g} \mathrm{L}^{-1}$ ) in $\mathrm{TiO}_{2} / \mathrm{UV}$ packed-bed flow-through reactor comparing efficiency in pure water (RO filtered water) - $\square$ and waste lagoon water - $\square$. (Error bars $=1 \mathrm{SD}, n=2$ )

In the work of Pelaez et al. (2011) the adsorption of $\mathrm{NOM}_{\text {to }} \mathrm{TiO}_{2}$ at different $\mathrm{pH}$ levels was investigated and it was found that the adsorption of NOM to the surface of the catalyst increased with decreasing $\mathrm{pH}$, with highest adsorption rates observed under acidic conditions ( $\mathrm{pH}$ 3.0). Other research has suggested that under acidic conditions another competing process could operate. Paul et al. (2007) suggested that the adsorption of fluoroquinolone (a synthetic antibiotic) to $\mathrm{TiO}_{2}$ could lead to the formation of a surface coordination complex that could facilitate the transfer of electrons from the conduction band of $\mathrm{TiO}_{2}$ to an appropriate electron acceptor, thus 
inhibiting the formation of the hydroxyl radicals that lead to the mineralisation of the target analyte. Pelaez et al. (2011) proposed that NOM might perform the same function, this, however, is unlikely as the neutral to mildly alkaline range $(\mathrm{pH} \mathrm{8.0)}$ ensures that the NOM predominantly acts as a radical species scavenger.

Thirumavalavan et al. (2012) have proposed that NOM and increased turbidity can hinder the photolysis of MC-LR at the UV irradiation wavelengths employed in the current study by reducing transmittance and light absorption. This would further account for the decreased removal of MC-LR in the waste lagoon water compared with the RO filtered water. He et al. (2012) also reported that NOM had a negative impact on MC removal their study, albeit much lower concentrations of both toxin and NOM were used/present in that study which was conducted in natural water samples from a lake and a river. Autin et al. (2013) demonstrated that background organic matter not only acts as a scavenger but may also saturate the catalyst's surface in their study investigating the photocatalytic degradation of the pesticide metaldehyde by UV/ $\mathrm{H}_{2} \mathrm{O}_{2}$ and $\mathrm{UV} / \mathrm{TiO}_{2}$. Khan et al. (2010) showed that the humic presence of humic acid.

High performance size exclusion chromatography (HPSEC) analysis of the protein indicate that the concentration of the humics and proteins decrease slightly in the control samples (figure $4 \mathrm{~B}$ and D) possibly due to photolysis in the UV only control and surface adsorption onto the $\mathrm{TiO}_{2}$ in the dark control. More significant changes, however, were observed in the protein and humics profiles following photocatalytic 
treatment (figure $4 \mathrm{~A}$ and $\mathrm{C}$ ) with the general trend in reduction in apparent molecular weight for both analyte groups suggesting significant degradation has taken place, reducing larger molecules to smaller fragments. Furthermore, the overall intensity of the signal for both proteins and humics has been reduced by around a third. This confirms that photocatalysis of the NOM occurs concurrently with the photocatalysis of $\mathrm{MC}$ accounting for the reduced $\mathrm{MC}$ removal efficiency in the waste lagoon water demonstrating, as might be expected, that $\mathrm{UV} / \mathrm{TiO}_{2}$ oxidation is non-selective. Another indicator of this is the fact that most of the water quality parameters improve, such as UV absorbance and transmittance at $254 \mathrm{~nm}$ (also indicative of NOM removal), colour and turbidity (which is in part due to NOM removal and in part due to the reactor acting as a filter), and dissolved organic carbon (again indicative of NOM removal; Supporting Information, S4).
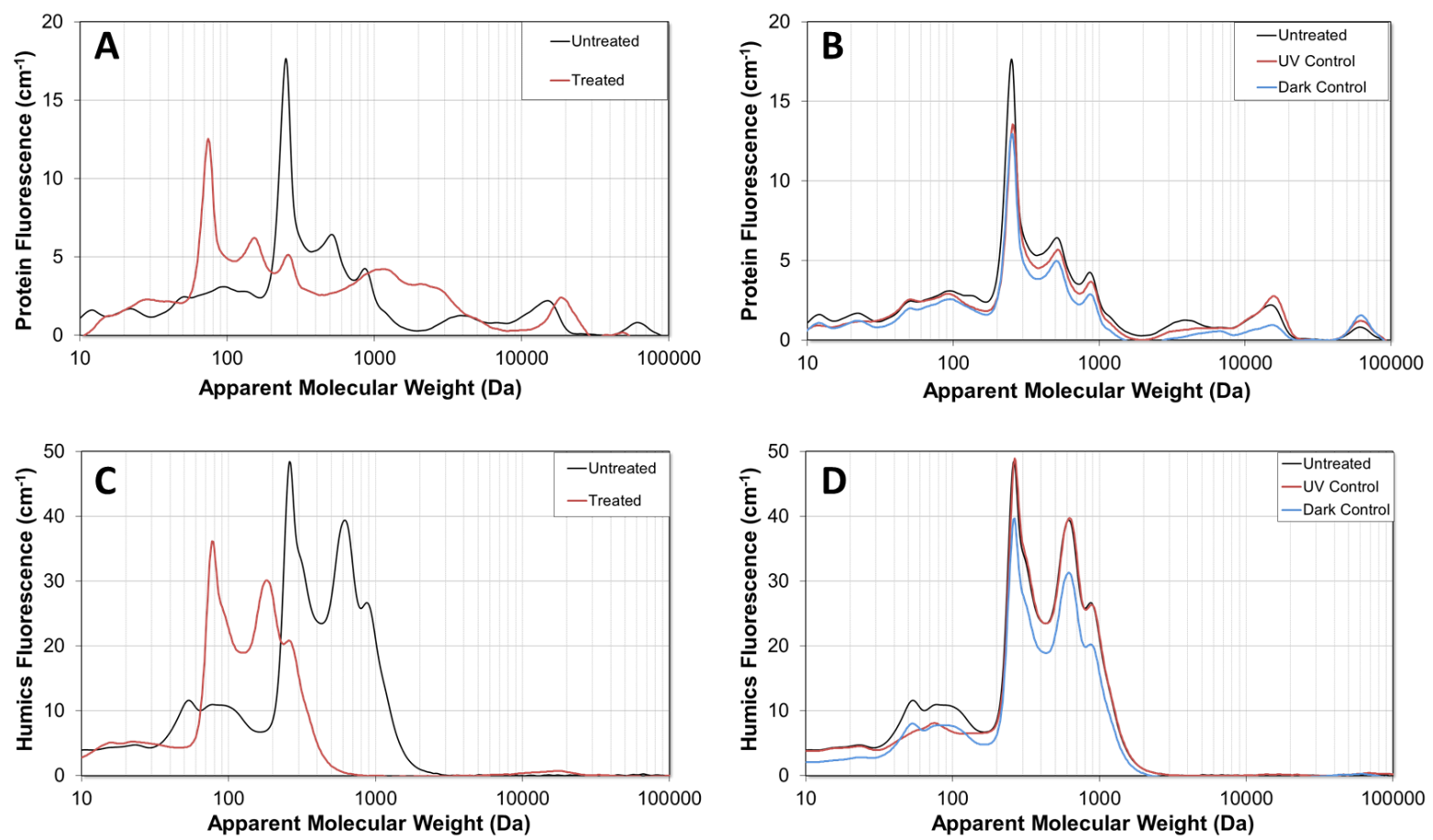
Figure 2: HPSEC determination of protein content ( $A$ and $B$ ) and humic acid content $(C$ and $D)$ in untreated waste lagoon samples and in $\mathrm{UV} / \mathrm{TiO}_{2}$ treated waste lagoon samples, and control samples (UV and dark controls).

\subsection{Evaluation of MC congener destruction in waste lagoon water}

257 Single microcystin analogues in waste lagoon water were passed through the reactor (Figure 3). The amount of dark adsorption (the initial binding of an organic pollutant to the titanium dioxide in the dark) can be an important determining factor in the removal rate of that pollutant (Feitz et al., 1999; Linda A Lawton et al., 2003). It has been observed in previous studies (Linda A Lawton et al., 2003; Pestana, 2012; impacts the dark adsorption of a given microcystin analogue.

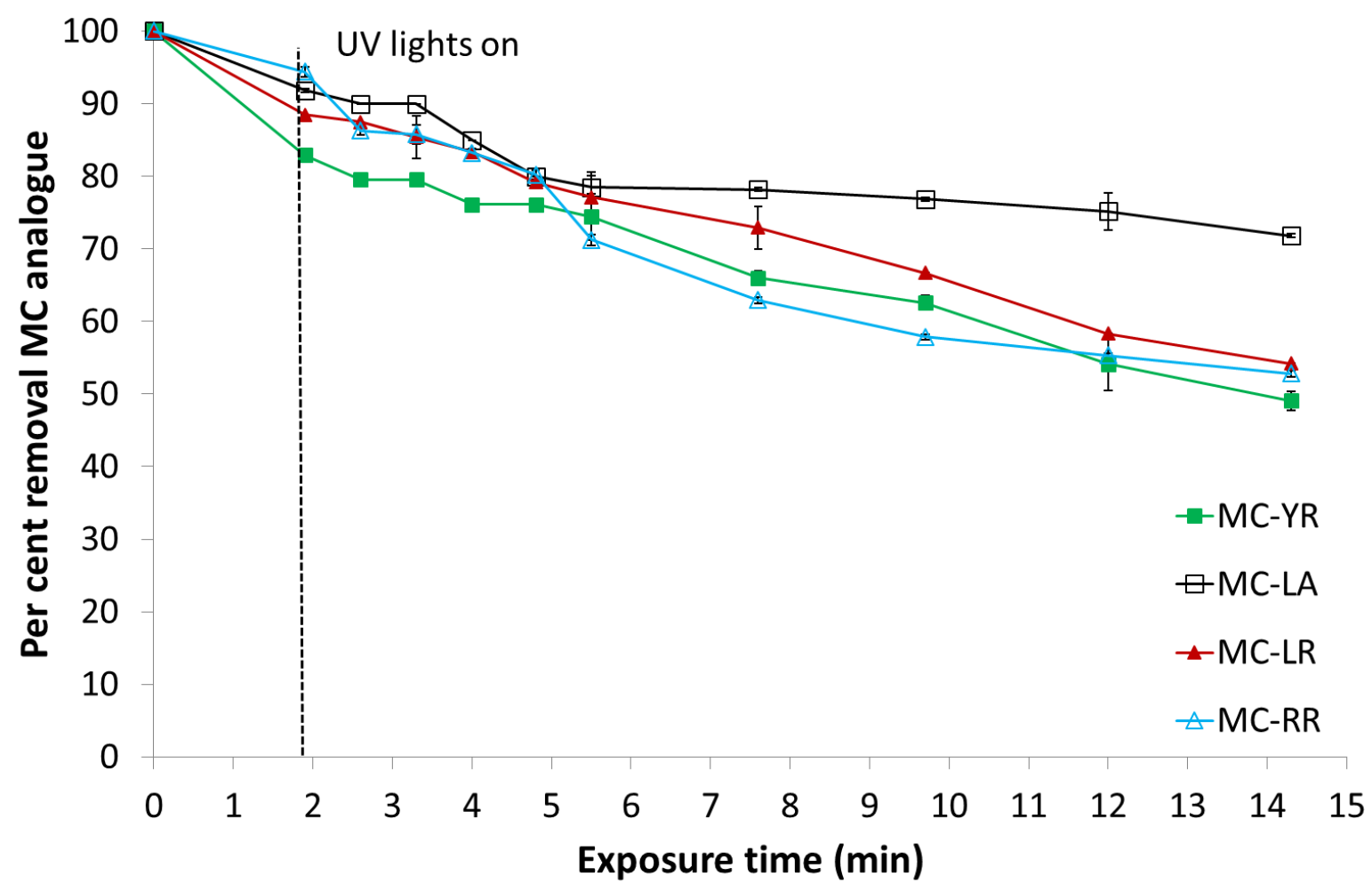


Figure 3: $\mathrm{TiO}_{2} / \mathrm{UV}$ packed-bed flow-through reactor removal of four individual microcystin analogues (30 $\mathrm{g} \mathrm{L} \mathrm{L}^{-1}$, respectively) in waste stabilisation lagoon water. (Error bars $=1 \mathrm{SD}, n=2$ )

In the present study, the four MC variants display slightly different dark adsorption ranging from 7\% (MC-RR) to 17\% (MC-YR). Direct comparison with previous studies is difficult as systems, including catalyst, light source, and physicochemical parameters vary significantly. Furthermore, the presence of NOM in the waste stabilisation lagoon water would further impact the dark adsorption of the MC analogues, due to competition for the binding sites on the catalyst, as was also observed by Autin et al. (2013). Despite the presence of NOM, and inorganic ions that can inhibit UV/TiO 2 photocatalys (Khan et al., 2010), in the water, breakdown of all four microcystin analogues can be observed. MC-YR underwent the greatest removal (51\%) after 14.3 min exposure time, followed by MC-RR 48\%, and MC-LR with $46 \%$ removal which all demonstrate similar efficiency. However, removal of MCLA was much lower, with around half the efficiency (28\%) showing an initial decline of around $20 \%$ in the first 5 min but removal slowing dramatically so that less than $10 \%$ is degraded in the subsequent time $(9.3 \mathrm{~min})$. One possible explanation for the lower oxidation of MC-LA may be due to the fact that the point of zero charge $\left(\mathrm{pH}_{\mathrm{zpc}}\right)$ for $\mathrm{TiO}_{2}$ was determined to be $\mathrm{pH} 6.25$ (Hoffmann et al., 1995), which means that below this value the surface of the $\mathrm{TiO}_{2}$ is positively charged and above this value the surface becomes negatively charged. According to Lawton and co-workers (Linda A Lawton et al., 2003), if the $\mathrm{pH}$ of the test solution is greater than the $\mathrm{pH}_{\mathrm{zpc}}$ the oxidation of cationic species would be favoured, whereas if the $\mathrm{pH}$ of the test solution is lower than the $\mathrm{pH}_{\mathrm{zpc}}$ the oxidation of anionic species would be favoured. This suggests that the oxidation of MC-LA is not favoured in the current study (initial $\mathrm{pH}$ of test solution 8.0) considering the net charge of MC-LA at $\mathrm{pH} 7.4$ is -2 
292 (Herfindal et al., 2009). While the net ionic charge of MC-YR, MC-LR, and MC-RR

293

294

295

296

297

298

299

300

301

302

303

304

305

306

307

308

309

310

311

312

313

314

315

may have been anionic (Rivasseau et al., 1998), they are less than MC-LA

(predicted charge of 0 or -1 ), which may explain the increased destruction of these analogues compared to MC-LA. Furthermore, it was determined by Rivasseau et al. (1998) that MC-YR is the least hydrophobic of the three MC they investigated, followed by MC-LR, and finally MC-RR at $\mathrm{pH} 7$, leading to MC-LA being less likely to be adsorbed onto the catalyst surface. While surface adsorption is not essential for degradation, it has been suggested that when molecules are adsorbed the surface they are held in close proximity to the site of hydroxyl radical production (Lawton et al., 2003), hence their degradation is more efficient. Rivasseau and co-workers (1998) also found MC-YR was adsorbed (13\% at $\mathrm{pH} 6.7)$ to natural suspended matter in river water samples slightly more so than MC-LR (11\%), and MC-RR (9\%). These observations are similar to those in the current study with initial adsorption: MC-YR $17 \%$; MC-LR 11\%; MC-RR $7 \%$. The results in the present study agree with previous studies (Lawton et al., 2003; Pestana et al., 2015; Shephard et al., 1998), that the efficiency of removal of different microcystin analogues in a photocatalytic system will depend on the variable amino acid composition of the MC analogue (and $\mathrm{pH}$ of the system) due to charge, hydrophobicity influences, and the differing susceptibility of various amino acid groups to oxidation, which was demonstrated in oxidation by chlorination where a reactivity order of $M C-Y R>M C-R R>M C-L R>M C-L A$ has been found (Ho et al., 2006b).

In addition to determining the photocatalytic efficiency of the reactor with single MC analogues, a mixture of all four analogues was investigated to determine whether direct competition affected the photocatalysis of the different MC (Figure 4). 


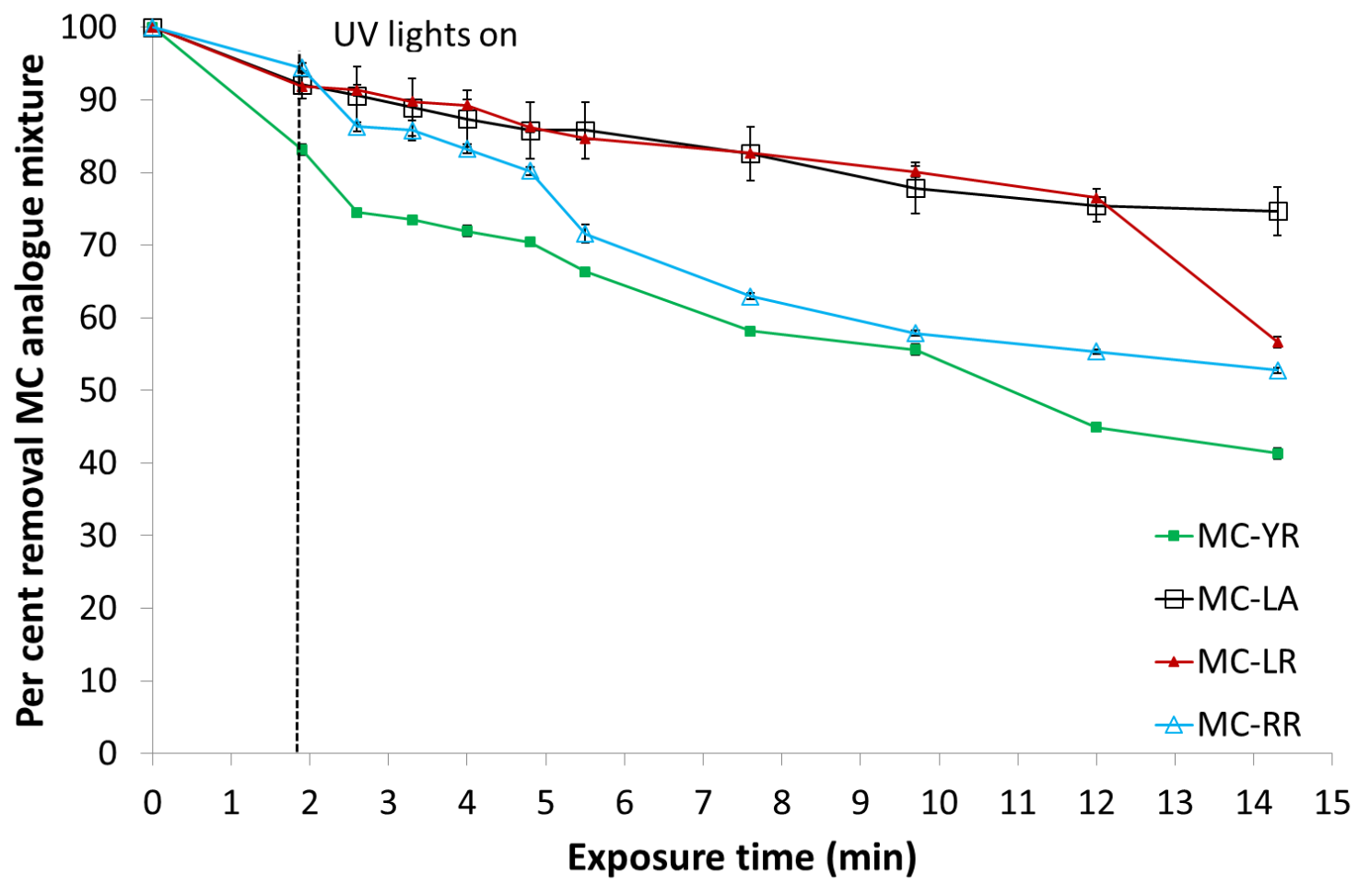

Figure. 4: $\mathrm{TiO}_{2} / \mathrm{UV}$ packed-bed flow-through reactor removal of a mixture of four microcystin analogues (10 $\mathrm{g} \mathrm{L}^{-1}$ of each analogue) in waste stabilisation lagoon water. (Error bars=1 SD, $n=2$ )

The amount of dark adsorption remains constant for three of the variants (MC-LR increases slightly from 8 to $11 \%$ ) suggesting little competition between the analogues as might be expected considering the relative concentrations of the analogues compared to the other dissolved organics (DOC $23.8 \mathrm{mg} \mathrm{L}^{-1}$; Table S3). Despite much lower background interference in their study Rimoldi et al. (2017) also reported no decreased removal of their target analytes (tetracycline, caffeine, paracetamol, atenolol) by $\mathrm{TiO}_{2}$ photocatalysis when they were present in a mixture. The removal of MC-RR, MC-LA and MC-LR remained very similar (3\% less removal for MC-LA and-LR) while the removal of MC-YR was also similar there was an increased from 51 to $59 \%$. This confirmed that MC-YR is more readily removed than the other three analogues, regardless of whether it was treated as a single or mixed array of MC. This will be of relevance in applying this technology to naturally MC contaminated water because it has often been observed that multiple $\mathrm{MC}$ are 
present during bloom events. Furthermore, it demonstrates the importance of not directly extrapolating predicted efficiencies from trials with different analogues.

The mechanism of the photocatalytic destruction of microcystins has been previously reported in a number of detailed studies by Liu et al. (2003), Song et al. (2007) and Antoniou et al. (Antoniou et al., 2008a, 2008b). Using LC-MS to identify by-products of the photocatalytic process, Liu et al. suggested the main processes involved in the photocatalytic decomposition process were a UV photo-isomerisation followed by hydroxyl radical attack and direct oxidation of the microcystin molecule. Song et al. proposed that UVC light would be required for the photo-isomerisation process and this could not be initiated by UVA light. Antoniou et al. [45] subsequently proposed that the isomerisation may have been induced by hydroxyl radical attack on the diene bonds of the ADDA group on the microcystin. Again using LC-MS to identify intermediates, Antoniou and co-workers [46] reported a total of eleven new intermediates that were not detected in the study by Liu et al. It should be noted that this study was conducted at $\mathrm{pH} 5.7$ using immobilised film reactors, while Liu used a slurry reactor. The complex matrix (waste water) used in the current study prevented the elucidation of degradation (by-)products. A common concern in the degradation potentially harmful pollutants is the danger represented by degradation products displaying a similar, or, in fact, higher toxicity than the parent molecule. This is not usually the case for microcystins. As elucidated by the studies of Antoniou et al. (2008a, 2008b), the first location of hydroxyl radical attack is the ADDA moiety of the microcystin molecule. The attack in several steps changes the arrangement of this moiety (Antoniou et al., 2008a). Several studies have shown that the ADDA moiety is primarily responsible for the toxicity of microcystins (An and Carmichael, 1994;

Dawson, 1998; Luukkainen et al., 1994; Trogen et al., 1996), therefore it can be 
concluded that the degradation intermediated of the photocatalytic removal of microcystins does not lead to the creation of more toxic compounds, but rather a detoxification of the solution.

\subsection{Photocatalysis of Microcystis aeruginosa cells}

Evidence from the literature suggests that titanium dioxide is capable of inactivating cyanobacteria (Hong et al., 2005; Kim and Lee, 2005). According to Malato et al. (2009) the susceptibility of microorganisms to photo-inactivation is (from least to most susceptible): protozoa, bacterial spores, mycobacteria, viruses, fungi, bacteria. Furthermore, there is a ranking of susceptibility within the group of bacteria with Gram-positive bacteria being less susceptible than Gram-negative bacteria due to differences in the structural complexity of the cell wall (Lydakis-Simantiris et al., 2010). According to the aforementioned ranking the common MC-producing cyanobacteria $M$. aeruginosa which has a Gram negative cell wall should show susceptibility to photocatalytic inactivation. Treatment in the packed-bed flow-through reactor found that the photocatalytic process had no effect on cell numbers (Supporting Information, S5). The number of cells remains stable in the treatment as well as the two controls (UV control and dark control). It is likely that reactor design, while effective for dissolved MC, is not appropriate for the treatment of cyanobacterial cells. When successful removal of microorganisms is reported in the literature they typically report the use of a static system, nano-particulate or thin film catalysts, and/or long contact times (Baram et al., 2011; Benabbou et al., 2011; Hong et al., 2005; Kim and Lee, 2005; Prasad et al., 2009; van Grieken et al., 2009a, 2009b). The flow-through system used in this study provided only limited treatment exposure (14.3 mins), which may not be sufficient considering other studies (Hong et 

and four days. The study did, however, show that extracellular MC (MC-LR, -YR, $\mathrm{RR}$ ) released from the $M$. aeruginosa were photocatalysed (figure 5).

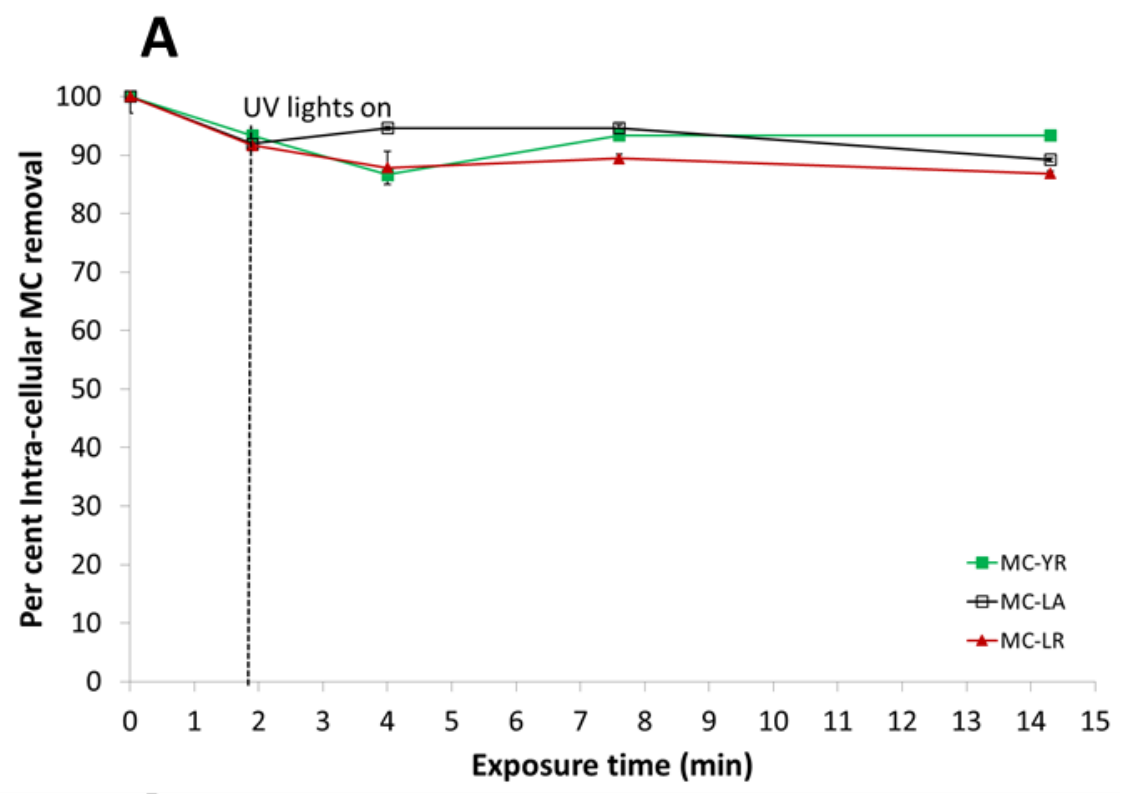

B

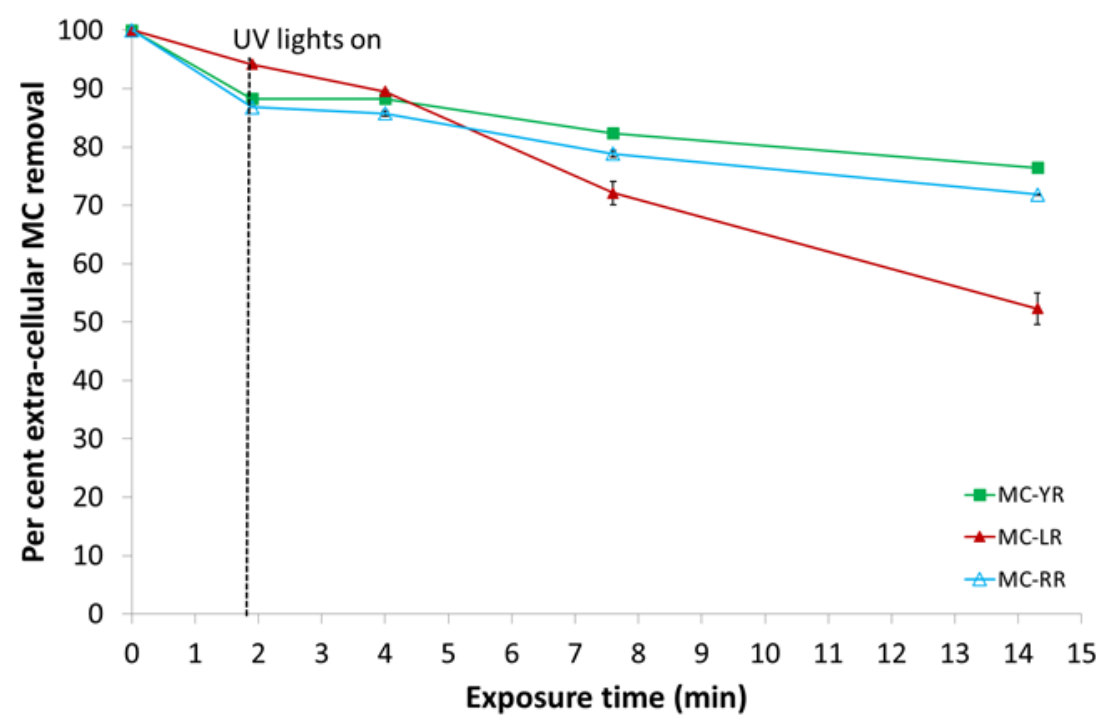

Figure 5: $\mathrm{TiO}_{2} / \mathrm{UV}$ packed-bed flow-through reactor removal of intra- $(A)$ and extra-cellular (B) MC during the photocatalytic treatment of $M$. aeruginosa in waste stabilisation lagoon water. (Error bars $=1$ $\mathrm{SD}, n=2)$

High concentrations of MC-RR $\left(68 \mu \mathrm{g} \mathrm{L}^{-1}\right)$ were found to be present in the culture and a reduction in $\mathrm{MC}-\mathrm{RR}$ concentration of $28 \%$ was observed. Lower concentrations of MC-LR and MC-YR were also detected (8.6 and $3.4 \mu \mathrm{g} \mathrm{L}^{-1}$, 
respectively) which also degraded (48 and $24 \%$, respectively). These findings demonstrate that while whole cyanobacterial cells were unaffected by photocatalysis, the levels of dissolved MC analogues were reduced. A further indicator that the cells were not disrupted cell is that intra-cellular MC levels do not change during the photocatalysis.

\subsection{Conclusion}

The prevalence of microcystins in waste water can have serious implications for public health and safety depending on waste water effluent utilisation. Irrigation of food crops or of recreational areas can lead to human and animal intoxication, release into streams/rivers carries similar risks. This investigation has demonstrated the practical application of $\mathrm{TiO}_{2}$ photocatalysis for waste stabilisation lagoon effluent treatment. The current reactor configuration readily lends itself to a larger scale application: The packed-bed nature of the design removes the challenge of catalyst separation post treatment and the continuous flow ensures that effluent can constantly be treated without the need to revert to a batch application. One area the current reactor design could be improved on is the UV irradiation source, however, it was demonstrated in a previous study (Pestana, 2012) that UV light emitting diodes could easily replace the need for high powered and energy inefficient UV lamps. The presence of NOM in waste water effluent challenges the removal of MC, but as has been demonstrated does not negate the removal by photocatalysis. Using $\mathrm{a} \mathrm{TiO}_{2}$ packed-bed flow-through reactor full-scale application could provide a low maintenance, low cost treatment for the elimination of cyanotoxins (and other trace toxic pollutants) in low quality water in a format which could be deployed in diverse environments across the globe. 


\section{Supporting Information}

424 Additional information about the rationale behind catalyst selection (section S1), a 425 detailed description of the reactor design (section S2), light and dark controls for the 426 removal of MC-LR from waste stabilisation lagoon water (section S3), a detailed 427 analysis of water quality parameters in untreated, $\mathrm{UV} / \mathrm{TiO} 2$ treated and control samples (section S4), and cell viability data for the photocatalysis of $M$. aeruginosa (section S5).

\section{Acknowledgements}

432 This research was funded by the Australian Government Department of Education and Training through the Endeavour post-doctoral award (C.J. Pestana) and the Engineering and Physical Sciences Research Council (EPSRC) UK [EP/P029280/1]. The authors would like to thank Senior Technician Martin Harris and Laboratory Manager Edith Kozlik for the analysis of the toxin samples, DOC, and HPSEC analysis. Furthermore, the authors would like to thank Len Montgomery for proofreading the manuscript.

The authors declare no competing financial interest and no influence was taken by the funding source on the study design, conduct of the research and/or preparation 442 of the article. 


\section{References}

449

450

451

452

453

454

455

456

457

458

459

460

461

462

463

464

465

466

467

468

469

470

An, J.S., Carmichael, W.W., 1994. Use of a colorimetric protein phosphatase inhibition assay and enzyme linked immunosorbent assay for the study of microcystins and nodularins. Toxicon 32, 1495-1507. https://doi.org/10.1016/0041-0101(94)90308-5

Antoniou, M.G., Shoemaker, J.A., de la Cruz, A.A., Dionysiou, D.D., 2008a. LC/MS/MS structure elucidation of reaction intermediates formed during the TiO 2 photocatalysis of microcystin-LR. Toxicon 51, 1103-1118. https://doi.org/10.1016/j.toxicon.2008.01.018

Antoniou, M.G., Shoemaker, J.A., De La Cruz, A.A., Dionysiou, D.D., 2008b. Unveiling new degradation intermediates/pathways from the photocatalytic degradation of microcystin-LR. Environ. Sci. Technol. 42, 8877-8883. https://doi.org/10.1021/es801637z

Autin, O., Hart, J., Jarvis, P., MacAdam, J., Parsons, S.A., Jefferson, B., 2013. The impact of background organic matter and alkalinity on the degradation of the pesticide metaldehyde by two advanced oxidation processes: UV/H2O2 and UV/TiO2. Water Res. 47, 2041-2049. https://doi.org/10.1016/j.watres.2013.01.022

Baram, N., Starosvetsky, D., Starosvetsky, J., Epshtein, M., Armon, R., Ein-Eli, Y., 2011. Photocatalytic inactivation of microorganisms using nanotubular TiO2. Appl. Catal. B Environ. 101, 212-219. https://doi.org/10.1016/j.apcatb.2010.09.024

Barrington, D.J., Ghadouani, A., Ivey, G.N., 2013. Cyanobacterial and 
microcystins dynamics following the application of hydrogen peroxide to waste stabilisation ponds. Hydrol. Earth Syst. Sci. 17, 2097-2105. https://doi.org/10.5194/hess-17-2097-2013

Benabbou, A.K., Guillard, C., Pigeot-Rémy, S., Cantau, C., Pigot, T., Lejeune, P., Derriche, Z., Lacombe, S., 2011. Water disinfection using photosensitizers supported on silica. J. Photochem. Photobiol. A Chem. 219, 101-108. https://doi.org/10.1016/j.jphotochem.2011.01.023

Dawson, R.M., 1998. The Toxicology of Microcystins. Toxicon 36, 953-962.

Fabris, R., Chow, C.W.K., Drikas, M., Eikebrokk, B., 2008. Comparison of NOM character in selected Australian and Norwegian drinking waters. Water Res. 42, 4188-4196. https://doi.org/10.1016/j.watres.2008.06.023

Feitz, A.J., Waite, T.D., Jones, G.J., Boyden, B.H., Orr, P.T., 1999. Photocatalytic degradation of the blue green algal toxin microcystin-LR in a natural organicaqueous matrix. Environ. Sci. Technol. 33, 243-249. https://doi.org/10.1021/es970952d

Ghadouani, A., Coggins, L.X., 2011. Science, technology and policy for Water Pollution Control at the Watershed Scale: Current issues and future challenges. Phys. Chem. Earth 36, 335-341. https://doi.org/10.1016/j.pce.2011.05.011

He, X., Pelaez, M., Westrick, J.A., O'Shea, K.E., Hiskia, A., Triantis, T., Kaloudis, T., Stefan, M.I., de la Cruz, A.A., Dionysiou, D.D., 2012. Efficient removal of microcystin-LR by UV-C/H 202 in synthetic and natural water samples. Water Res. 46, 1501-1510. https://doi.org/10.1016/j.watres.2011.11.009 
Herfindal, L., Kasprzykowski, F., Schwede, F., Łankiewicz, L., Fladmark, K.E., Łukomska, J., Wahlsten, M., Sivonen, K., Grzonka, Z., Jastorff, B., Døskeland, S.O., 2009. Acyloxymethyl esterification of nodularin-R and microcystin-LA produces inactive protoxins that become reactivated and produce apoptosis inside intact cells. J. Med. Chem. 52, 5759-5762. https://doi.org/10.1021/jm900502e

Ho, L., Meyn, T., Keegan, A., Hoefel, D., Brookes, J., Saint, C.P., Newcombe, G., 2006a. Bacterial degradation of microcystin toxins within a biologically active $\begin{array}{llll}\text { sand } \quad \text { Wilter. } & \text { 768-774. }\end{array}$ https://doi.org/10.1016/j.watres.2005.12.009

Ho, L., Onstad, G., Gunten, U. Von, Rinck-Pfeiffer, S., Craig, K., Newcombe, G., 2006b. Differences in the chlorine reactivity of four microcystin analogues. Water Res. 40, 1200-1209. https://doi.org/10.1016/j.watres.2006.01.030

Hobson, P., Dickson, S., Burch, M., Thorne, O., Tsymbal, L., House, J., Brookes, J., Chang, D., Kao, S., Lin, T., Bierlein, K., Little, J., 2012. Alternative and Innovative Methods for Source Water Management of Algae and Cyanobacteria [Project \#4094].

Hoffmann, M.R., Martin, S.T., Choi, W., Bahnemann, D.W., 1995. Environmental Applications of Semiconductor Photocatalysis. Chem. Rev. 95, 69-96. https://doi.org/10.1021/cr00033a004

Hong, J., Ma, H., Otaki, M., 2005. Controlling algal growth in photo-dependent decolorant sludge by photocatalysis. J. Biosci. Bioeng. 99, 592-597. https://doi.org/10.1263/jbb.99.592

Khan, U., Benabderrazik, N., Bourdelais, A.J., Baden, D.G., Rein, K., Gardinali, 

P.R., Arroyo, L., O'Shea, K.E., 2010. UV and Solar TiO2 Photocatalysis of Brevetoxins (PbTxs). Toxicon 55, 1008-1016. https://doi.org/10.1016/j.toxicon.2009.11.014.UV

Kim, S.C., Lee, D.K., 2005. Preparation of TiO2-coated hollow glass beads and their application to the control of algal growth in eutrophic water. Microchem. J. $80,227-232$. https://doi.org/10.1016/j.microc.2004.07.008

Lawton, L.A., Edwards, C., Codd, G.A., 1994. Extraction and high performance liquid chromatographic method for determination of $\mathrm{MC}$ in raw and treated waters $11,1525-1530$.

Lawton, L.A., Robertson, P. k. J., 1999. Physico-chemical treatment methods for the removal of microcystins (cyanobacterial hepatotoxins) from potable waters. Chem. Soc. Rev. 28, 217-224. https://doi.org/10.1039/A805416I

Lawton, L.A., Robertson, P.K.J., Cornish, B.J.P.A., Marr, I.L., Jaspars, M., 2003. Processes influencing surface interaction and photocatalytic destruction of microcystins on titanium dioxide photocatalysts. J. Catal. 213, 109-113. https://doi.org/10.1016/S0021-9517(02)00049-0

Lawton, L.A., Robertson, P.K.J., Cornish, B.J.P.A., Marr, I.L., Jaspars, M., 2003. Processes influencing surface interaction and photocatalytic destruction of microcystins on titanium dioxide photocatalysts. J. Catal. 213, 109-113. https://doi.org/10.1016/S0021-9517(02)00049-0

Liu, I., Lawton, L.A., Bahnemann, D.W., Liu, L., Proft, B., Robertson, P.K.J., 2009. The photocatalytic decomposition of microcystin-LR using selected titanium dioxide materials. Chemosphere 76, 549-553. https://doi.org/10.1016/j.chemosphere.2009.02.067 
Liu, I., Lawton, L.A., Cornish, B., Robertson, P.K.J., 2002. Mechanistic and toxicity studies of the photocatalytic oxidation of microcystin-LR. J. Photochem. Photobiol. A Chem. 148, 349-354. https://doi.org/10.1016/S10106030(02)00062-X

Liu, I., Lawton, L.A., Robertson, P.K.J., 2003. Mechanistic studies of the photocatalytic oxidation of microcystin-LR: An investigation of byproducts of the decomposition process. Environ. Sci. Technol. 37, 3214-3219. https://doi.org/10.1021/es0201855

Luukkainen, R., Namikoshi, M., Sivonen, K., Rinehart, K.L., Niemelä, S.I., 1994. Isolation and identification of 12 microcystins from four strains and two bloom samples of Microcystis spp.: structure of a new hepatotoxin. Toxicon 32, 133139. https://doi.org/10.1016/0041-0101(94)90030-2

Lydakis-Simantiris, N., Riga, D., Katsivela, E., Mantzavinos, D., Xekoukoulotakis, N.P., 2010. Disinfection of spring water and secondary treated municipal wastewater by $\mathrm{TiO} 2$ photocatalysis. Desalination 250, 351-355. https://doi.org/10.1016/j.desal.2009.09.055

Malato, S., Fernández-Ibáñez, P., Maldonado, M.I., Blanco, J., Gernjak, W., 2009. Decontamination and disinfection of water by solar photocatalysis: Recent overview and trends. Catal. Today 147, 1-59. https://doi.org/10.1016/j.cattod.2009.06.018

Martins, J., Peixe, L., Vasconcelos, V.M., 2011. Unraveling Cyanobacteria Ecology in Wastewater Treatment Plants (WWTP). Microb. Ecol. https://doi.org/10.1007/s00248-011-9806-y

Nicholson, B.C., Rositano, J., Burch, M.D., 1994. Destruction of cyanobacterial 
peptide hepatotoxins by chlorine and chloramine. Water Res. 28, 1297-1303. https://doi.org/10.1016/0043-1354(94)90294-1

568

Paerl, H.W., Huisman, J., 2008. Blooms like it hot. Science (80-. ). https://doi.org/10.1126/science.1155398

Paul, T., Miller, P.L., Strathmann, T.J., 2007. Visible-light-mediated TiO2 photocatalysis of fluoroquinolone antibacterial agents. Environ. Sci. Technol. 41, 4720-4727. https://doi.org/10.1021/es070097q

Pelaez, M., de la Cruz, A.A., O'Shea, K., Falaras, P., Dionysiou, D.D., 2011. Effects of water parameters on the degradation of microcystin-LR under visible lightactivated TiO2 photocatalyst. Water Res. 45, 3787-3796. https://doi.org/10.1016/j.watres.2011.04.036

Pelaez, M., Falaras, P., Likodimos, V., Kontos, A.G., de la Cruz, A.A., O'shea, K., Dionysiou, D.D., 2010. Synthesis, structural characterization and evaluation of sol-gel-based NF-TiO2 films with visible light-photoactivation for the removal of microcystin-LR. Appl. Catal. B Environ. 99, 378-387. https://doi.org/10.1016/j.apcatb.2010.06.017

Pestana, C.J., 2012. Monitoring and controlling cyanobacterial metabolites (microcystin and geosmin) in aqueous systems. Robert Gordon University Aberdeen.

Pestana, C.J., Edwards, C., Prabhu, R., Robertson, P.K.J., Lawton, L.A., 2015. Photocatalytic degradation of eleven microcystin variants and nodularin by TiO2 coated glass microspheres. J. Hazard. Mater. 300, 347-353. https://doi.org/10.1016/j.jhazmat.2015.07.016 
Pestana, C.J., Robertson, P.K.J., Edwards, C., Wilhelm, W., McKenzie, C., Lawton, L.A., 2014. A continuous flow packed bed photocatalytic reactor for the destruction of 2-methylisoborneol and geosmin utilising pelletised $\mathrm{TiO}_{2}$. Chem. Eng. J. 235, 293-298. https://doi.org/10.1016/j.cej.2013.09.041

Praptiwi, R.A., Pestana, C.J., Sawade, E.T., Swain, N., Schroeder, G., Newcombe, G., 2017. Treatment challenge of a cyanobacterium Romeria elegans bloom in a South Australian wastewater treatment plant-a case study. Environ. Technol. (United Kingdom) 38, $782-788$. https://doi.org/10.1080/09593330.2016.1262454

Prasad, G.K., Agarwal, G.S., Singh, B., Rai, G.P., Vijayaraghavan, R., 2009. Photocatalytic inactivation of Bacillus anthracis by titania nanomaterials. J. Hazard. Mater. 165 , 506-510. https://doi.org/10.1016/j.jhazmat.2008.10.009

Rimoldi, L., Meroni, D., Falletta, E., Pifferi, V., Falciola, L., Cappelletti, G., Ardizzone, S., 2017. Emerging pollutant mixture mineralization by TiO2 photocatalysts. The role of the water medium. Photochem. Photobiol. Sci. 16, 60-66. https://doi.org/10.1039/c6pp00214e

Rivasseau, C., Martins, S., Hennion, M.C., 1998. Determination of some physicochemical parameters of microcystins (cyanobacterial toxins) and trace level analysis in environmental samples using liquid chromatography. J. Chromatogr. A 799, 155-169. https://doi.org/10.1016/S00219673(97)01095-9

Robertson, P.K.J., Lawton, L.A., Münch, B., Rouzade, J., 1997. Destruction of cyanobacterial toxins by semiconductor photocatalysis. Chem. Commun. 
Shephard, G.S., Stockenström, S., De Villiers, D., Engelbrecht, W.J., Sydenham, E.W., Wessels, G.F.S., 1998. Photocatalytic degradation of cyanobacterial microcystin toxins in water. Toxicon 36, 1895-1901. https://doi.org/10.1016/S0041-0101(98)00110-X

Sivonen, K., Jones, G., 1999. Toxic Cyanobacteria in water: A guide to their public health consequences, monitoring and management. WHO Press, London.

Song, W., Bardowell, S., O'Shea, K.E., 2007. Mechanistic study and the influence of oxygen on the photosensitized transformations of microcystins (Cyanotoxins). Environ. Sci. Technol. 41, 5336-5341. https://doi.org/10.1021/es063066o

Spoof, L., Catherine, A., 2017. Tables of Microcystins and Nodularins, in: Meriluoto, J., Spoof, L., Codd, G.A. (Eds.), Handbook of Cyanobacterial Monitoring and Cyanotoxin Analysis. John Wiley and Sons Ltd., Chichester, UK, pp. 526-537.

Thirumavalavan, M., Hu, Y.L., Lee, J.F., 2012. Effects of humic acid and suspended soils on adsorption and photo-degradation of microcystin-LR onto samples from Taiwan reservoirs and rivers. J. Hazard. Mater. 217-218, 323-329. https://doi.org/10.1016/j.jhazmat.2012.03.031

Trogen, G.B., Annila, A., Eriksson, J., Kontteli, M., Meriluoto, J., Sethson, I., Zdunek, J., Edlund, U., 1996. Conformational studies of microcystin-LR using NMR spectroscopy and molecular dynamics calculations. Biochemistry 35, 3197-3205. https://doi.org/10.1021/bi952368s 
636 Umar, M., Aziz, H.A., 2013. Photocatalytic Degradation of Organic Pollutants in 637 Water, Organic Pollutants - Monitoring, Risk and Treatment. InTech Open 638 Acess Publishing. https://doi.org/http://dx.doi.org/10.5772/57353

639 van Grieken, R., Marugán, J., Sordo, C., Martínez, P., Pablos, C., $2009 a$. 640 Photocatalytic inactivation of bacteria in water using suspended and 641 immobilized silver-TiO2. Appl. Catal. B Environ. 93, 112-118. https://doi.org/10.1016/j.apcatb.2009.09.019

van Grieken, R., Marugán, J., Sordo, C., Pablos, C., 2009b. Comparison of the photocatalytic disinfection of E. coli suspensions in slurry, wall and fixed-bed

Catal.

Today 144 $48-54$. https://doi.org/10.1016/j.cattod.2008.11.017

WHO, 2017. WHO - Guidelines on drinking water quality - fourth edition. Geneva, 648 Switzerland. 